\title{
Influence of early childhood burns on school performance: an Australian population study
}

\author{
Nadin Azzam, ${ }^{1}$ Ju-Lee Oei, ${ }^{2,3}$ Susan Adams, ${ }_{1}^{3,4}$ Barbara Bajuk, ${ }^{5}$ Lisa Hilder, ${ }^{6}$ \\ Abdel-Latif Mohamed, ${ }^{7}$ Ian M R Wright, ${ }^{8}$ Andrew J A Holland ${ }^{9,10}$
}

\begin{abstract}
- Additional material is
published online only. To view please visit the journal online (http://dx.doi.org/10.1136/ archdischild-2017-313355).
\end{abstract}

For numbered affiliations see end of article.

\section{Correspondence to}

Professor Andrew J A Holland, Department of Paediatric Surgery, The Children's Hospital at Westmead, Westmead, NSW 2145, Australia; andrew.holland@health.nsw. gov.au

Received 8 May 2017 Revised 24 October 2017 Accepted 30 October 2017 Published Online First 29 November 2017
Check for updates

To cite: Azzam N, Oei J-L, Adams $\mathrm{S}$, et al. Arch Dis Child 2018:103:444-451.

\section{ABSTRACT}

Objectives To determine the influence of burn injuries on childhood performance in national standardised curriculum-based school tests.

Design Birth and health records of 977 children who were hospitalised with a burn injury between 2000 and 2006 in the state of New South Wales, Australia, were linked to performance scores in the National Assessment Program: Literacy and Numeracy test, a compulsory nationwide curriculum-based test (CBT) and compared with children who were not hospitalised for burns and who were matched for birth year, gender, gestation and socioeconomic status.

Main outcome measures Test scores in years 3 (ages 8-9), 5 (ages 10-11) and 7 (ages 13-14) in numeracy, writing, reading, spelling, grammar and punctuation.

Results Mean age at first burn injury was 28 months (median: 20, range: 0-140). Children with burns were significantly more likely to have younger mothers (28.5 vs 29.6years) $(P<0.001)$, be indigenous (OR $2.5(95 \% \mathrm{Cl}$ 2.1 to 3.1)) $(P<0.001)$ and have siblings (OR $1.2(95 \%$ $\mathrm{Cl} 1.1$ to 1.4$))(\mathrm{P}<0.001)$. They were also less likely to meet national minimum standards in most domains of testing until year 5 , even after adjustment for parental education levels, parental smoking, maternal age and indigenous status. Each 10\% increase in total body surface area burnt was associated with a decrease in year 5 scores by $37.0 \%$ in numeracy and $71.9 \%$ in writing.

Conclusions Most childhood burn injuries occur before the start of formal schooling. Children who are hospitalised for burns perform more poorly in CBT even after accounting for family and socioeconomic disadvantage. Rehabilitation of children with burn injuries must address school performance to decrease any long-term negative societal impact of burns.

\section{INTRODUCTION}

Burns are a frequent and serious cause of injury in children. ${ }^{1-3}$ In Australia, at least $1 \%$ of children below 5 years of age will experience a burn injury and over half will be injured seriously enough to be affected in their daily lives. ${ }^{4}$ Some children need to be hospitalised, sometimes for prolonged periods. Unfortunately, hospitalisation of any form may increase the risk of adverse psychosocial and learning sequelae, as children are removed from normal daily activities and interaction with families and peers. $^{5}$

Burns are now an uncommon direct cause of death in developed countries. ${ }^{1}$ The long-term sequelae of burn survivors are therefore of paramount

\section{What is already known on this topic?}

- Burn injuries are more common in children with relative socioeconomic disadvantage.

- Children with relative socioeconomic disadvantage also have burn injuries that lead to poorer outcomes, including school performance.

\section{What this study adds?}

Burns in childhood are associated with poorer performance in curriculum-based tests up to at least 5 years after the injury.

- Severe and more extensive burns increase the risk of poor school outcomes.

- Children with burn injuries should be supported even after the burns have physically healed.

importance. ${ }^{1-3}$ Recovery may often require multiple subsequent admissions for wound dressings, reparative operations and other related procedures. For children, this may lead to considerable psychosocial consequences as hospitalisation, regardless of duration, isolates them from normal interactions with family and peers at school. Further, these effects may extend into adulthood. ${ }^{1-5}$

Previous data show that adult survivors of childhood burns are at an increased risk of mental and physical problems, including depression, anxiety disorders, substance abuse, suicidal attempts, arthritis, fractures and respiratory morbidities ${ }^{6}$ which all have the potential to impair quality of life for the patient as well as their families and society. ${ }^{6}$

The causes of poor adult outcomes after childhood burn injury remain uncertain. Any form of burn injury may prevent regular school attendance, a critical contributor to school performance. ${ }^{5}$ In turn, poor academic outcomes increase the risk of poor adult functioning, physical health, psychological dysfunction and social maladjustment. ${ }^{5-7}$ The effects of school failure are also far reaching and can extend for generations. ${ }^{8}$ Early identification of children at risk of school failure for intervention and support may therefore considerably mitigate the detriments of school failure even until the third decade of life. ${ }^{7}$

Children may start school several years after a burn injury and may be physically healthy at school entry. Providing a rationale for long-term follow-up, particularly for psychosocial sequelae 
in children without physical health problems, is difficult in any resource-challenged environment without evidence of need.

In this study, we sought to determine if childhood burn injuries are associated with poorer performance in standardised curriculum-based tests (CBT) by examining linked health and education data for all children hospitalised for a burn injury in the state of New South Wales (NSW) in Australia between 2000 and 2006. We hypothesised that burn injuries sustained during childhood would worsen performance in CBT and that the magnitude of school failure would correlate to the severity of the burn.

\section{METHODS}

\section{Study design}

This was a population linkage study using routinely collected data from health and educational records for all children born between 2000 and 2006 in the state of NSW, Australia, and who were hospitalised for a burn injury in this period.

\section{Databases and patient selection}

The databases used for this study were:

1. The Perinatal Data Collection (PDC) providing prenatal, delivery and postnatal (to hospital discharge) data for mothers and their infants registered in NSW who were either born alive or dead of at least 20 weeks' gestation or at a minimum birth weight of $400 \mathrm{~g}$.

2. The Admitted Patients Data Collection (APDC) provides information on all episodes of care to NSW residents in public, private, psychiatric and repatriation facilities in NSW and within Australia. Each episode of care was categorised according to the International Statistical Classification of Diseases and Related Health Problems 10th Revision-Australian Modification (ICD-10-AM) with the trauma codes T20-T98 defining the burn injury and its characteristics (see table 1$)^{3}$

\begin{tabular}{|c|c|}
\hline T20-25 & Burns of external surface specified by site \\
\hline T26-28 & Burns confined to eye and internal organs \\
\hline T29-32 & Burns of multiple and unspecified body regions \\
\hline T90-98 & Injury and other consequences from burns \\
\hline $\begin{array}{l}\text { Total body surface area (TBSA) of } \\
\text { burn } \\
\text { Burn injuries were classified } \\
\text { according to TBSA, according to } \\
\text { the ICD-10-AM trauma codes } \\
\text { T31.0-31.9. }\end{array}$ & $\begin{array}{l}1=<10 \% \\
2=10 \%-19 \% \\
3=20 \%-29 \% \\
4=30 \%-39 \% \\
5=40 \%-49 \% \\
6=50 \%-59 \% \\
7=60 \%-69 \% \\
8=70 \%-79 \% \\
9=80 \%-89 \% \\
10=90 \%-99 \%\end{array}$ \\
\hline $\begin{array}{l}\text { Degree of burn injury } \\
\text { Another measure of burn severity, } \\
\text { related to burn thickness. Classified } \\
\text { by ICD-10-AM trauma codes into } \\
\text { first, second and third-degree burns }\end{array}$ & $\begin{array}{l}0=\text { unspecified degree } \\
1=\text { first-degree burn } \\
2=\text { second-degree burn } \\
3=\text { third-degree burn }\end{array}$ \\
\hline $\begin{array}{l}\text { Burn injury with sequelae } \\
\text { Sequelae of burns derived from } \\
\text { ICD codes: } \\
\text { T95.0, 95.1, 95.2, 95.3, 95.4, 95.8, } \\
95.9\end{array}$ & $\begin{array}{l}1=\text { with sequelae } \\
0=\text { without sequelae }\end{array}$ \\
\hline
\end{tabular}

3. The Registry of Births, Deaths and Marriages and the Australian Coordinating Registry Cause of Death Unit Record File, containing ICD-10 codes for causes of all deaths in NSW that do not require a coronial inquiry from 1997.

4. The National Assessment Plan for Literacy and Numeracy (NAPLAN). This is a CBT that commenced in 2008 and is completed by all Australian children in year levels 3, 5, 7 and 9. Since year 9 NAPLAN results were not available at the time, this study analysed the results of year 3, 5 and 7 NAPLAN tests. Approximately 1000000 Australian children sit these assessments in each year level, with performance assessed in five domains-grammar and punctuation, reading, spelling, writing and numeracy. ${ }^{8-11}$ Australian schools are divided into primary school, comprising years kindergarten through year 6 , and secondary school comprising years 7-12. The dispersion of NAPLAN assessments across a child's primary and secondary schooling in years 3 (ages 7-9), 5 (ages 9-11) and 7 (ages 11-13) enables longitudinal assessment of their academic progress. Information retrieved for this study includes parental education levels, school sector, attendance of exams and raw NAPLAN scores. These are scored out of 100 for each domain, translated into bands which are then used to determine whether the student performed below the national minimum standard (NMS). All scores are graded according to the same scale across year levels. The NMS is the minimum band above which all normal children in Australia are expected to achieve. Failure to achieve the NMS indicates that a child will have difficulties in progressing to the next level of schooling without assistance. ${ }^{8-11}$ The NAPLAN is compulsory for children in all Australian schools. The tests are conducted on the same day in May each year and the results are released on the same day in September of the same year.

\section{Linkage}

The Centre for Health Record Linkage, ${ }^{12}$ a dedicated record linkage facility affiliated with the NSW Ministry of Health, performed the data linkage required for this study. Each patient record was deidentified and assigned a unique project-specific person number, which enabled researchers to correctly link deidentified patient health and education records across the multiple data sets within the project. Linkage rates for NSW children without burns to a NAPLAN record were higher $(877$ 833 of $1105338,79.4 \%$ ) than for children with burns (977 of $1556,62.8 \%$ ) or to matched controls (3692 of $6200,59.5 \%$, $\mathrm{P}<0.001)$.

\section{Patient selection}

Children with birth dates from January 2000 to December 2006 were eligible to sit NAPLAN up to 2011. Children born after 2006 would have been too young to have sat for the NAPLAN within the period of this study and APDC diagnoses were only available from July 2000. Three groups of children were identified and compared. ${ }^{1}$ The burn injury cohort consisted of children registered in the PDC in the designated time period who were also registered in the APDC with an ICD-10-AM diagnosis correlating to a burn injury up to the year 2011. Children included in this cohort may have had a burn injury as the primary reason for admission, or as a secondary or tertiary diagnosis. The hospital burn admission criteria include all burn injuries $>5 \%$ total body surface area (TBSA), any burn injury to special sites, associated with an inhalational burn or due to chemical or electrical exposure. In addition, burns with a TBSA $<5 \%$ in 
children would also be admitted if there was a suspicion of non-accidental injury, if the child has multiple comorbidities or other trauma, or if there are concerns of the child's social situation or compliance with dressings. More severe TBSA burns would be transferred to specialised burns unit. ${ }^{2}$ The children with burns were matched in a 4:1 ratio with children who were born in the same time period and also registered in the APDC, but not with a burn injury for gender, Socio-Economic Index For Area and gestational age. This means that the control population was children who had been hospitalised for reasons other than burn injuries. ${ }^{3}$ The rest of the NSW population excluded children who died before reaching an eligible age to sit the NAPLAN (including perinatal deaths) or who sustained a burn injury after they had sat for at least one NAPLAN test. This provided us with a second control population that had neither suffered a burn injury nor required an admission to hospital (online supplementary appendix A).

\section{Statistical analysis}

Comparisons of categorical data were conducted with $\chi^{2}$ analyses for the baseline characteristics or Fisher's exact test for samples with $<5$ subjects. Percentages with ORs and 95\% CIs were expressed for proportions, means (SD) and medians (ranges) for continuous data in the baseline characteristics. Analyses of variance for unbalanced data were conducted on NAPLAN scores, expressed as difference of means. Univariate logistic regression analyses and a multiple binary logistic regression model with backward elimination investigated the impact of burn injury on scoring below NMS when controlling for other confounders. Burn injury was the primary independent variable. Others included attendance at a school in a major city, attending a government school, parental school education level and parental education beyond schooling years, indigenous status, smoking during pregnancy, mental and behavioural comorbidities (as defined by ICD-10-AM codes F00-F98), previous pregnancies and maternal age (1-8, see table 2$)$. Estimates of association were reported as ORs with two-sided 95\% CIs. ${ }^{6}$ A Hosmer-Lemeshow goodness-of-fit test ${ }^{6}$ was conducted on the year 3 analysis to confirm if this model appropriately fit the data.

Table 2 Baseline maternal and infant characteristics

\begin{tabular}{llll}
\hline Variable & $\begin{array}{l}\text { Burns (\%) } \\
\mathbf{n}=1556\end{array}$ & $\begin{array}{l}\text { Matched } \\
\text { controls (\%) } \\
\mathbf{n}=6200\end{array}$ & P value \\
\hline Maternal characteristics & & & \\
\hline Age & $28.5(6.0)$ & $29.6(5.6)$ & $<0.001$ \\
\hline Indigenous & $176(11.3)$ & $258(4.5)$ & $<0.001$ \\
\hline Multiparous & $994(63.9)$ & $3662(59.1)$ & $<0.001$ \\
\hline Smoked during pregnancy & $406(26.5)$ & $1061(17.5)$ & $<0.001$ \\
\hline Vaginal delivery & $1042(67.0)$ & $3790(61.1)$ & $<0.001$ \\
\hline Maternal diabetes & $8(0.5)$ & $4(0.6)$ & 0.49 \\
\hline Gestational diabetes & $63(4.1)$ & $289(4.7)$ & 0.31 \\
\hline Hypertension & $5(0.3)$ & $44(0.7)$ & 0.08 \\
\hline Immigrant & $665(42.7)$ & $2781(44.9)$ & 0.14 \\
\hline Rural & $534(34.2)$ & $1978(31.9)$ & 0.07 \\
\hline Birth weight (g) & 3361.4 & 3381.9 & 0.15 \\
\hline Infant characteristics & & & 0.58 \\
\hline Mean gestational age (weeks) & 39 & 39 & 0.92 \\
\hline Preterm (<37 weeks) & $124(8.0)$ & $488(7.9)$ & 0.66 \\
\hline Admission into an NICU & $275(17.7)$ & $1126(18.2)$ & \\
\hline
\end{tabular}

NICU, neonatal intensive care unit.
Linear regression models served to analyse associations between time duration after a burn injury in years, percentage burn TBSA, months follow-up in hospital and NAPLAN scaled scores. Estimates of association were reported with SEs and t-values. Statistical significance was calculated at $\mathrm{P}<0.05$ using the SAS V.9.4 statistical software.

\section{RESULTS}

Up to 1119440 paediatric patients were registered in the NSW PDC between July 2000 and December 2006. Of these, 7041 were stillbirths and 3085 died within the neonatal period (<29 days of age), leaving a total of 1108513 survivors. Of these, 1556 were admitted to a NSW hospital with a burn injury before the age of 13 .

\section{Maternal characteristics}

Maternal characteristics are summarised in table 2. Mothers of children with burns were significantly younger than control mothers, twice as likely to be indigenous, more likely to have smoked during pregnancy and be multiparous $(\mathrm{P}<0.001)$.

\section{Characteristics of children with burns}

The median age at the first burn injury was 20 months (range: $0-140)$. Most $(76.0 \%)$ patients were younger than 5 years of age when they sustained a burn injury. The majority of patients $(87.5 \%)$ had $<10 \%$ TBSA burnt. Others $(5.4 \%, 83)$ had $>20 \%$ and $(7.1 \%, 111)$ had between $10 \%$ and $20 \%$ TBSA burnt. Most children $(40.9 \%, 673)$ sustained deep partial thickness burns while 9.7\% (151) had a full thickness burn. Only $1.0 \%$ of patients were burned in more than two regions. The most commonly burnt regions were the hand and wrist $(680$, $43.7 \%)$. This was followed by trunk $(422,27.1 \%)$, hip and lower limb $(421,27.1 \%)$ and shoulder and upper hand (392, $25.2 \%)$. Children with burns spent a median of 8 days in hospital for each episode of care.

\section{Length of stay and hospitalisations}

Children with burn injuries experienced a higher accumulated time in hospital than the matched controls. Total length of stay (LOS) for burns in children was 15339 days (mean 9.86, median 8) compared with 35250 days (mean 5.66, median 6) for controls $(\mathrm{P}<0.001)$. The mean LOS per admission for control patients (M: 3.58, SD: 6.53) was actually slightly higher than for children with burn injuries (M: 3.27, SD: 7.02), t(2.39), $\mathrm{P}=0.0168$.

\section{Mortality}

Seven $(0.5 \%)$ of the 1556 children with burns died in hospital (compared with 18 of 6200 controls $(0.3 \%$, OR $1.55,95 \% \mathrm{CI}$ 0.65 to $3.70, \mathrm{P}=0.32)$ ). Three deaths were directly attributable to the cause of the burn (a fire, each child was aged 1-2 years), three died from an unclear cause and one death was attributed to a burn injury caused by a motor vehicle accident.

\section{NAPLAN RESULTS}

Significantly more children with burns were absent from a test $(2.6 \%$ vs $0.5 \%, \mathrm{P}<0.001)$ compared with matched controls, although test absences decreased from year $3(3.7 \%)$ to year 7 $(1.6 \%)$ in the burns cohort. Mean test scores for children with burn injuries were significantly lower than either controls or the rest of the children of NSW $(\mathrm{P}<0.05)$ in every test domain but this difference decreased with age (see table 3 ). The year 7 mean scores show the least significance in difference between means. Only one significantly lower mean was found 
Table 3 Differences in mean test scores for children with burns, matched controls and rest of NSW population

\begin{tabular}{|c|c|c|c|c|c|c|c|c|}
\hline & $\begin{array}{l}\text { Burns versus } \\
\text { controls }(95 \% \mathrm{Cl})\end{array}$ & $P$ value & $\begin{array}{l}\text { Burns versus rest of NSW } \\
(95 \% \mathrm{Cl})\end{array}$ & $P$ value & $\begin{array}{l}\text { df between } \\
\text { groups }\end{array}$ & $\begin{array}{l}\text { df within } \\
\text { groups }\end{array}$ & F value & $P$ value \\
\hline \multicolumn{9}{|l|}{ Year 3} \\
\hline Grammar & $-29.00(-36.10$ to -21.79$)$ & $<0.001$ & $-36.11(-42.50$ to -29.70$)$ & $<0.001$ & 2 & 485951 & 70.52 & $<0.001$ \\
\hline Reading & $-27.70(-34.20$ to -21.09$)$ & $<0.001$ & $-33.40(-39.20$ to 27.52$)$ & $<0.001$ & 2 & 485339 & 69.43 & $<0.001$ \\
\hline Spelling & $-25.50(-31.50$ to -19.40$)$ & $<0.001$ & $-30.89(-36.28$ to -25.49$)$ & $<0.001$ & 2 & 485951 & 70.07 & $<0.001$ \\
\hline Writing & $-16.90(-22.01$ to -11.80$)$ & $<0.001$ & $-24.80(-29.40$ to -20.30$)$ & $<0.001$ & 2 & 485294 & 78.50 & $<0.001$ \\
\hline Numeracy & $-19.60(-25.40$ to -13.80$)$ & $<0.001$ & $-25.40(-30.60$ to -20.30$)$ & $<0.001$ & 2 & 484990 & 56.21 & $<0.001$ \\
\hline \multicolumn{9}{|l|}{ Year 5} \\
\hline Grammar & $-26.20(-33.90$ to -18.50$)$ & $<0.001$ & $-33.40(-40.30$ to -26.60$)$ & $<0.001$ & 2 & 477705 & 54.21 & $<0.001$ \\
\hline Reading & $-18.80(-25.80$ to -11.80$)$ & $<0.001$ & $-26.10(-32.40$ to -20.00$)$ & $<0.001$ & 2 & 477165 & 43.31 & $<0.001$ \\
\hline Spelling & $-22.40(-28.90$ to -15.90$)$ & $<0.001$ & $-26.20(-32.00$ to 20.50$)$ & $<0.001$ & 2 & 477705 & 42.92 & $<0.001$ \\
\hline Writing & $-18.60(-24.70$ to -12.50$)$ & $<0.001$ & $-30.90(-36.30$ to -25.40$)$ & $<0.001$ & 2 & 477024 & 98.13 & $<0.001$ \\
\hline Numeracy & $-16.30(-23.10$ to -9.50$)$ & $<0.001$ & $-22.20(-28.20$ to -16.20$)$ & & 2 & 475480 & 32.79 & $<0.001$ \\
\hline \multicolumn{9}{|l|}{ Year 7} \\
\hline Grammar & $-13.40(-24.0$ to -2.90$)$ & 0.01 & $-17.00(-26.40$ to -7.70$)$ & $<0.001$ & 2 & 462674 & 7.43 & $<0.001$ \\
\hline Reading & $-8.70(-17.90$ to -0.50$)$ & 0.07 & $-15.60(-23.80$ to -7.45$)$ & $<0.001$ & 2 & 461380 & 12.12 & $<0.001$ \\
\hline Spelling & $-12.50(-21.80$ to -3.20$)$ & 0.01 & $-14.40(-22.70$ to -6.20$)$ & $<0.001$ & 2 & 462674 & 6.28 & $<0.001$ \\
\hline Writing & $-17.30(-27.20$ to -7.30$)$ & $<0.001$ & $-33.80(-42.60$ to -24.90$)$ & $<0.001$ & 2 & 462148 & 52.97 & $<0.001$ \\
\hline Numeracy & $-14.10(-24.90$ to -3.30$)$ & 0.01 & $-13.80(-23.40$ to -4.240$)$ & 0.01 & 2 & 462704 & 4.01 & $<0.05$ \\
\hline
\end{tabular}

NSW, New South Wales.

in numeracy results of children with burn injuries compared with controls. The difference in means between burn injuries and controls (average of 13.2 points) was less significant than the difference in means between burn injuries and the rest of the NSW population (average of 18.9 points, $\mathrm{P}<0.01$, table 4).

\section{Factors associated with failure to reach NMS}

Factors associated with poor school performance were examined using univariate and then multivariate logistic regression to determine the relationship between a burn injury and other factors with failure to meet NMS (table 5). The influence of burn injuries was only significant in year 3 across all domains of testing (OR 1.41, 95\% CI 1.18 to 1.68 , online supplementary appendix B). Factors increasing risk of not meeting NMS that persisted until high school included: schooling in a government (public) facility, having a multiparous mother or a mother who smoked during pregnancy and being indigenous (see tables 3 and 4). The year 7 multivariable regression showed the most significant associations between prenatal factors such as smoking during pregnancy (OR 2.09, 95\% CI 1.50 to 2.90 ) and indigenous status (OR 2.65, 95\% CI 1.50 to 2.91). Conversely, the lower scholastic performance observed in children with burn injuries appeared to be ameliorated in those attending a metropolitan school or with a mother over 35 years of age.

Table 4 ANOVA analysis comparing mean scores of burns, matched controls and rest of NSW population

\begin{tabular}{|c|c|c|c|c|c|c|c|c|}
\hline & $\begin{array}{l}\text { Burns versus controls } \\
(95 \% \mathrm{Cl})\end{array}$ & $P$ value & $\begin{array}{l}\text { Burns versus rest of NSW } \\
(95 \% \mathrm{Cl})\end{array}$ & $P$ value & $\begin{array}{l}\text { df between } \\
\text { groups }\end{array}$ & $\begin{array}{l}\text { df within } \\
\text { groups }\end{array}$ & F value & $P$ value \\
\hline \multicolumn{9}{|l|}{ Year 3} \\
\hline Grammar & $-29(-36.1$ to 21.79$)$ & $<0.001$ & $-36.11(-42.5$ to 29.7$)$ & $<0.001$ & 2 & 485951 & 70.52 & $<0.001$ \\
\hline Reading & $-27.7(-34.2$ to 21.09$)$ & $<0.001$ & $-33.4(-39.20$ to 27.52$)$ & $<0.001$ & 2 & 485339 & 69.43 & $<0.001$ \\
\hline Spelling & $-25.5(-31.5$ to 19.4$)$ & $<0.001$ & $-30.89(-36.28$ to 25.49$)$ & $<0.001$ & 2 & 485951 & 70.07 & $<0.001$ \\
\hline Writing & $-16.9(-22.01$ to 1.8$)$ & $<0.001$ & -24.8 (-29.4 to 20.3$)$ & $<0.001$ & 2 & 485294 & 78.5 & $<0.001$ \\
\hline Numeracy & $-19.6(-25.4$ to 13.8$)$ & $<0.001$ & $-25.4(-30.6$ to 20.3$)$ & $<0.001$ & 2 & 484990 & 56.21 & $<0.001$ \\
\hline \multicolumn{9}{|l|}{ Year 5} \\
\hline Grammar & $-26.2(-33.9$ to 18.5$)$ & $<0.001$ & $-33.4(-40.3$ to -26.6$)$ & $<0.001$ & 2 & 477705 & 54.21 & $<0.001$ \\
\hline Reading & $-18.8(-25.8$ to 11.8$)$ & $<0.001$ & $-26.1(-32.4$ to -20.0$)$ & $<0.0001$ & 2 & 477165 & 43.31 & $<0.001$ \\
\hline Spelling & $-22.4(-28.9$ to 15.9$)$ & $<0.001$ & $-26.2(-32.0$ to -20.5$)$ & $<0.0001$ & 2 & 477705 & 42.92 & $<0.001$ \\
\hline Writing & $-18.6(-24.7$ to 12.5$)$ & $<0.001$ & $-30.9(-36.3$ to -25.4$)$ & $<0.0001$ & 2 & 477024 & 98.13 & $<0.001$ \\
\hline Numeracy & $-16.3(-23.1$ to 9.5$)$ & $<0.001$ & $-22.2(-28.2$ to -16.2$)$ & $<0.001$ & 2 & 475480 & 32.79 & $<0.001$ \\
\hline \multicolumn{9}{|l|}{ Year 7} \\
\hline Grammar & $-13.4(-24.0$ to -2.9$)$ & 0.0123 & $-17(-26.4$ to -7.7$)$ & 0.0004 & 2 & 462674 & 7.43 & 0.0006 \\
\hline Reading & $-8.7(-17.9$ to -0.5$)$ & 0.0626 & $-15.6(-23.8$ to -7.45$)$ & 0.0002 & 2 & 461380 & 12.12 & $<0.0001$ \\
\hline Spelling & $-12.5(-21.8$ to -3.2$)$ & 0.0082 & $-14.4(-22.7$ to -6.2$)$ & 0.0006 & 2 & 462674 & 6.28 & 0.0019 \\
\hline Writing & $-17.3(-27.2$ to -7.3$)$ & 0.0007 & $-33.8(-42.6$ to -24.9$)$ & $<0.0001$ & 2 & 462148 & 52.97 & $<0.0001$ \\
\hline Numeracy & $-14.1(-24.9$ to -3.3$)$ & 0.0103 & $-13.8(-23.4$ to -4.24$)$ & 0.014 & 2 & 462704 & 4.01 & 0.0182 \\
\hline
\end{tabular}

ANOVA, analysis of variance; NSW, New South Wales. 
Table 5 Associations with failure to reach national minimum standards in year levels 3, 5 and 7

\begin{tabular}{|c|c|c|c|c|c|c|}
\hline \multirow[b]{2}{*}{ Association } & \multicolumn{3}{|c|}{ Univariate analysis } & \multicolumn{3}{|c|}{ Multivariate analysis } \\
\hline & SE & OR $(95 \% \mathrm{Cl})$ & $P$ value & SE & OR $(95 \% \mathrm{Cl})$ & $P$ value \\
\hline \multicolumn{7}{|l|}{ Year 3} \\
\hline City school & 0.08 & $0.73(0.63$ to 0.85$)$ & $<0.001$ & 0.09 & $0.93(0.79$ to 1.11$)$ & 0.42 \\
\hline Government school & 0.09 & 1.95 (1.63 to 2.34$)$ & $<0.001$ & 0.10 & 1.61 (1.32 to 1.97$)$ & $<0.001$ \\
\hline Parent with high school education & 0.08 & $0.42(0.36$ to 0.49$)$ & $<0.001$ & 0.09 & 0.61 (0.51 to 0.73 ) & $<0.001$ \\
\hline Indigenous status & 0.08 & 2.79 (2.37 to 3.29$)$ & $<0.001$ & 0.17 & 2.00 (1.42 to 2.78 ) & $<0.001$ \\
\hline Mother $>35$ years old & 0.01 & 0.94 (0.93 to 0.95$)$ & $<0.001$ & 0.01 & 0.96 (0.94 to 0.97 ) & $<0.001$ \\
\hline \multicolumn{7}{|l|}{ Year 5} \\
\hline Burn injury & 0.10 & 1.49 (1.23 to 1.79$)$ & $<0.001$ & 0.11 & 1.18 (0.96 to 1.45$)$ & 0.12 \\
\hline City school & 0.09 & 0.65 (0.55 to 0.78$)$ & $<0.001$ & 0.10 & 0.83 (0.68 to 1.01$)$ & 0.06 \\
\hline Smoking during pregnancy & 0.10 & 2.76 (2.29 to 3.34$)$ & $<0.001$ & 0.11 & 1.69 (1.36 to 2.11$)$ & $<0.001$ \\
\hline Indigenous status & 0.16 & 5.30 (3.85 to 7.31$)$ & $<0.001$ & 0.18 & 1.85 (1.56 to 2.34 ) & $<0.001$ \\
\hline Mother $>35$ years old & 0.01 & 0.94 (0.93 to 0.96$)$ & $<0.001$ & 0.01 & 0.95 (0.93 to 0.97 ) & $<0.001$ \\
\hline \multicolumn{7}{|l|}{ Year 7} \\
\hline Burn injury & 0.14 & 1.34 (1.03 to 1.75$)$ & $<0.05$ & 0.14 & 1.13 (0.84 to 1.54$)$ & 0.42 \\
\hline City school & 0.13 & 0.59 (0.46 to 0.76$)$ & $<0.001$ & 0.16 & 0.80 (0.59 to 1.08$)$ & 0.15 \\
\hline Government school & 0.14 & 2.75 (2.10 to 3.61$)$ & $<0.001$ & 0.15 & 2.24 (1.63 to 3.09 ) & $<0.001$ \\
\hline Parent with high school education & 0.12 & $0.46(0.36$ to 0.58$)$ & $<0.001$ & 0.18 & 0.65 (0.48 to 0.88 ) & $<0.05$ \\
\hline Previous pregnancy & 0.12 & 1.30 (1.02 to 1.65$)$ & $<0.05$ & 0.16 & 1.41 (1.04 to 1.92$)$ & $<0.05$ \\
\hline Smoking during pregnancy & 0.14 & 3.27 (2.50 to 4.28$)$ & $<0.001$ & 0.17 & 2.09 (1.50 to 2.91$)$ & $<0.001$ \\
\hline Indigenous status & 0.25 & 5.00 (3.08 to 8.11$)$ & $<0.001$ & 0.27 & 2.65 (1.55 to 4.50$)$ & $<0.001$ \\
\hline
\end{tabular}

\section{Effects of burns and hospitalisation on test scores}

Linear regression was used on the cohort with burn injuries alone to analyse the effect of duration between time of burn and NAPLAN assessment, number of follow-up hospitalisations and severity of TBSA on NAPLAN scores (table 6). In regard to duration of time since burn injury, the most significant results $(\mathrm{P}<0.001)$ were shown in year 5 , where NAPLAN scores were increased an average of 4.8 points for each year following the burn injury, showing that as the duration of time since the burn injury lengthened, the NAPLAN scores improved.

Linear regression also demonstrated that for every added month of hospitalisation for children with burns, year 3 NAPLAN scores decreased in spelling ( $\mathrm{t}$-value: -2.37 ) and writing ( $\mathrm{t}$-value: -2.43 ) by 0.2 points $(\mathrm{P}<0.05)$. With every $10 \%$ increase in TBSA burn severity, year 5 domains showed large decreases ranging from 37 points in numeracy ( $\mathrm{t}$-value: -3.42 ) to 71.9 points in writing (t-value: -6.00$)$.

\section{DISCUSSION}

This is the first study to objectively link school performance with childhood burn injury. We have demonstrated a clear disparity in school performance between children with and without burns, even after controlling for socioeconomic and gender differences. The differences were most prominent in primary school but persisted even for older children. We also found that the negative effect of burns on school performance increased with the severity of burns and with the age at which the burns were sustained, both findings which would tend to support this association.
More extensive burns and a shorter duration between time of burn injury and time of test had worse outcomes.

There are, of course, mitigating circumstances towards a longterm outcome such as school performance. Indeed, there is a well-documented significant association between socioeconomic and family disparity to the risk of burn injuries. ${ }^{9-14}$ This further highlights the need for support of any child with a burn injury as the factors that increase the risk of burns are also similar to those increasing the risk of poor academic outcomes. ${ }^{9-14}$ Follow-up may be difficult in this cohort due to the time difference between the burn injury and the start of school for the child: the median age of burns in children in our study was 20 months, about 2.5 years before starting school for most Australian children. The improvement of NAPLAN scores as time since burn injury increased does highlight the acute nature of burn injuries and suggests that the concentration of impacts manifests earlier in a child's life after the initial incident. Therefore, a child's development postburn injury is amenable to improvement and this improvement may be facilitated by better rehabilitation. In addition, there was some evidence that the adverse impact of the burn injury might be reduced if the children attended a metropolitan school or if the mother was over 35 years of age. These findings may reflect easier access to medical care and improved financial resources typically associated with a more mature family unit.

The association between TBSA severity and poorer academic outcomes in year 5 suggests that the trauma of the burn injury exerts an independent risk in affecting school performance. It is well documented that increase in severity of the burn increases 
Table 6 Linear regression on effects of years after burn injury, months follow-up in hospital and burn severity by TBSA on mean NAPLAN scores

\begin{tabular}{|c|c|c|c|c|}
\hline Domain & Estimate & SE & t-value & $P$ value \\
\hline \multicolumn{5}{|c|}{$\begin{array}{l}\text { Effect of increase in years after burn injury, by year on NAPLAN average } \\
\text { performance }\end{array}$} \\
\hline \multicolumn{5}{|l|}{ Year 3} \\
\hline Grammar and punctuation & 2.81 & 1.34 & 2.11 & $<0.05$ \\
\hline Reading & 1.56 & 1.28 & 1.22 & 0.22 \\
\hline Spelling & 2.48 & 1.18 & 2.10 & $<0.05$ \\
\hline Writing & 0.8 & 1.11 & 0.72 & 0.47 \\
\hline Numeracy & 1.41 & 1.07 & 1.32 & 0.19 \\
\hline \multicolumn{5}{|l|}{ Year 5} \\
\hline Grammar and punctuation & 5.36 & 1.18 & 4.53 & $<0.001$ \\
\hline Reading & 4.11 & 1.07 & 3.84 & $<0.001$ \\
\hline Spelling & 5.34 & 1.15 & 4.65 & $<0.001$ \\
\hline Writing & 5.14 & 1.17 & 4.40 & $<0.001$ \\
\hline Numeracy & 4.13 & 1.06 & 3.89 & $<0.001$ \\
\hline \multicolumn{5}{|l|}{ Year 7} \\
\hline Grammar and punctuation & 0.90 & 1.80 & 0.50 & 0.6168 \\
\hline Reading & 0.79 & 1.41 & 0.56 & 0.5786 \\
\hline Spelling & 2.47 & 1.51 & 1.64 & 0.1020 \\
\hline Writing & 0.99 & 1.59 & 0.62 & 0.5349 \\
\hline Numeracy & 0.77 & 1.48 & 0.52 & 0.6044 \\
\hline \multicolumn{5}{|c|}{$\begin{array}{l}\text { Effect of increased follow-up in hospitalisation, by month on NAPLAN } \\
\text { average performance }\end{array}$} \\
\hline \multicolumn{5}{|c|}{ Year 3} \\
\hline Grammar and punctuation & -0.16 & 0.10 & -1.62 & 0.11 \\
\hline Reading & -0.05 & 0.10 & -0.52 & 0.61 \\
\hline Spelling & -0.21 & 0.09 & -2.37 & $<0.05$ \\
\hline Writing & -0.20 & 0.08 & -2.43 & $<0.05$ \\
\hline \multicolumn{5}{|l|}{ Numeracy } \\
\hline \multicolumn{5}{|l|}{ Year 5} \\
\hline Grammar and punctuation & 0.00 & 0.09 & 0.01 & 0.99 \\
\hline Reading & -0.04 & 0.08 & -0.50 & 0.62 \\
\hline Spelling & 0.07 & 0.09 & 0.82 & 0.41 \\
\hline Writing & -0.06 & 0.09 & -0.67 & 0.51 \\
\hline \multicolumn{5}{|l|}{ Numeracy } \\
\hline \multicolumn{5}{|l|}{ Year 7} \\
\hline Grammar and punctuation & -0.11 & 0.10 & -1.05 & 0.30 \\
\hline Reading & -0.15 & 0.08 & -1.76 & 0.08 \\
\hline Spelling & -0.06 & 0.09 & -0.65 & 0.51 \\
\hline Writing & -0.1368 & 0.09 & -1.48 & 0.14 \\
\hline
\end{tabular}

Effect of increase in TBSA by $10 \%$ on NAPLAN average performance Year 3

\begin{tabular}{|llllr|}
\hline Grammar and punctuation & 8.63 & 15.93 & -0.54 & 0.59 \\
\hline Reading & -26.08 & 14.99 & -1.74 & 0.08 \\
\hline Spelling & -29.84 & 14.17 & -2.11 & $<0.05$ \\
\hline Writing & -8.04 & 12.94 & -0.62 & 0.53 \\
\hline Numeracy & -12.4 & 12.6 & -0.98 & 0.32 \\
\hline Year 5 & & & & \\
\hline Grammar and punctuation & -50.04 & 12.53 & -4.00 & $<0.001$ \\
\hline Reading & -34.56 & 11.16 & -3.10 & $<0.05$ \\
\hline Spelling & -47.61 & 11.22 & -4.24 & $<0.001$ \\
\hline Writing & -71.89 & 11.98 & -6.00 & $<0.001$ \\
\hline Numeracy & -37.01 & 10.81 & -3.42 & $<0.001$ \\
\hline Year 7 & & & & \\
\hline Grammar and punctuation & 0.38 & 4.31 & 0.09 & 0.93 \\
\hline
\end{tabular}

\begin{tabular}{|c|c|c|c|c|}
\hline Domain & Estimate & SE & t-value & $P$ value \\
\hline \multicolumn{5}{|l|}{ Reading } \\
\hline Spelling & -3.54 & 3.51 & -1.01 & 0.31 \\
\hline Writing & 11.23 & 4.18 & 2.69 & $<0.05$ \\
\hline Numeracy & -1.87 & 3.59 & -0.52 & 0.60 \\
\hline \multicolumn{5}{|c|}{ Rates of burn severity by TBSA in burn injury cohort } \\
\hline TBSA (\%) & Rate (\%) & & & \\
\hline$<10$ & $1362(87.5)$ & & & \\
\hline 10-19 & $132(8.5)$ & & & \\
\hline $20-29$ & $36(2.3)$ & & & \\
\hline $30-39$ & $14(0.9)$ & & & \\
\hline $40-49$ & $8(0.5)$ & & & \\
\hline $50-59$ & $1(0.1)$ & & & \\
\hline 60-69 & 0 & & & \\
\hline 70-79 & 0 & & & \\
\hline 80-89 & $1(0.1)$ & & & \\
\hline $90-99$ & $2(0.2)$ & & & \\
\hline
\end{tabular}

NAPLAN, National Assessment Plan for Literacy and Numeracy; TBSA, total body surface area.

the risk of complications including further admissions, infections, scarring and surgeries. ${ }^{15-17}$ These factors may perhaps explain the association between the burn severity and academic outcomes.

Previous studies using self-assessment tools such as parent ${ }^{18}$ or healthcare professional ${ }^{16}$ surveys have found similar negative outcomes on academic outcomes but to date, and to our knowledge, there are no other published data on objective educational outcomes for children after a burn injury.

The association between burn injuries and educational outcomes is complex and is most likely intertwined with socioeconomic and family influences as well as health issues according to the current literature. ${ }^{9-14}$ Children with burns may need repeated hospitalisations ${ }^{1}$ and this disrupts the sequence of learning and peer interaction. Indeed, data show that academic performance is related to intelligence and school attendance. ${ }^{17}$ 19-21 Early identification (eg, from the time of the burn injury) to provide support for the children may have far-reaching ramifications, even into subsequent generations. ${ }^{7}$

One of the strengths of our study lies in the high linkage rates between burn injury admissions and education data. We obtained data from all three Australian school sectors (Catholic, government and independent), while previous studies linking only government schools were able to achieve linkage rates of only $56 \% .^{22}$ The reasons for failure to link NAPLAN results to certain children cannot be determined from this study. Linkage rates are decreased if the identifiers are weak (eg, multiple name and address changes), but children may also move or not turn up for a test due to illness or parental objection (although this is not frequent in NSW). We found that matched children without burns had similar linkage rates to the rest of the children in NSW, suggesting that the burn injury itself was a significant association in lower linkage rates, perhaps due to higher rates of non-attendance for the test. This may in fact underestimate the poor academic outcomes of children with burn injuries as non-attendance of tests may be an indicator of long-standing school disruptions, although the exact reason for the lower linkage rate cannot be known.

Unfortunately, we did not have data on school attendance: both this and other factors should be examined in future studies 
to better determine the mechanism by which burn injuries and subsequent disruptions may be associated with children failing to achieve their academic potential. Our study, nevertheless, shows that the long-term outcomes of any child admitted into hospital for burn injuries must not be neglected. The repercussions of an early life injury may not be appreciable until long after it has occurred. Other important factors that could potentially be explored in future studies include psychosocial sequelae, family support needs and the success of school reintegration programmes in order to clarify the mechanism by which burn injuries could contribute to poorer academic outcomes. This is a vital step to recognise as poor school outcomes will have devastating effects on both a personal and societal level, with important cost implications. ${ }^{23}$ This flags the importance for clinicians in primary healthcare settings to identify children at increased risk of burn injuries and with more tailored prevention, intervention strategies and rehabilitation programmes improve the long-term outcomes of these children.

This project has identified several risk factors and associations that contribute to the impact of burns on a child's quality of life. More detailed prospective studies which delve into each of these risk factors may provide additional information on the question of the mechanism by which burn injuries affect longterm outcomes. Since academic performance influences a child's confidence, professional and social participation later in life, this places a great priority on clinicians to seek more efficient rehabilitation strategies with paediatric patients with burns. Some protective factors that could be explored in future research include ensuring support for family, psychosocial interventions and school rehabilitation interventions that span primary and secondary schools.

\section{CONCLUSION}

Our study has demonstrated an association between burn injuries and poorer academic outcomes. More severe burn injuries were associated with worse school outcomes, although as the time since the burn injury increased, school outcomes also improved. While it may not be possible for the children to return to school in a timely fashion because of their injuries, strategies could be put in place to minimise the children's displacement from mainstream learning and regular interaction with their peers. Future research into the psychosocial, family and health implications of burn injuries might elucidate the complex association between the burn injury and poorer academic outcomes. A better understanding of this association would provide potential targeted solutions to facilitate improved educational outcomes for both the child and their family well beyond completion of any physical treatment of the burn injury.

\footnotetext{
Author affiliations

${ }^{1}$ School of Women's and Children's Health, University of New South Wales, Sydney, New South Wales, Australia

${ }^{2}$ Royal Hospital for Women, Randwick, New South Wales, Australia

${ }^{3}$ University of New SouthWales, School of Women's and Children's Health, Randick, New South Wales, Australia

${ }^{4}$ Sydney Children's Hospital, Randwick, New South Wales, Australia

${ }^{5}$ Pregnancy and Newborn Services Network, Sydney Children's Hospitals Network, Westmead, New South Wales, Australia

${ }^{6}$ National Perinatal Epidemiology and Statistics Unit, University of New South Wales School of Women's and Children's Health and Centre for Big Data Research in Health, Randwick, New South Wales, Australia

${ }^{7}$ Department of Neonatology, Centenary Hospital for Women and Children, Canberra, ACT, Australia

${ }^{8}$ Illawarra Health and Medical Research Institute, University of Wollongong, Wollongong, New South Wales, Australia

${ }^{9}$ Department of Paediatric Surgery, Children's Hospital at Westmead, Westmead, New
} South Wales, Australia
${ }^{10}$ Discipline of Child and Adolescent Health, Sydney Medical School, University of Sydney, Sydney, New South Wales, Australia

Acknowledgements We thank Dr Kylie-Ann Mallitt, Centre for Big Data Research in Health, University of New South Wales, for advice with the statistical analysis.

Contributors The primary author of this article is NA, a final year medical student at the University of New South Wales. JLO was the primary supervisor over the research process, was responsible for developing the project idea, obtaining ethics approval and gaining access to the linked data sets. AJAH was the second main supervisor in the research, guiding the research question with his expertise in the field of paediatric burns and contributing to the development of the project idea and its aims. SA, BB and LH were involved in guidance over the statistical analysis of the data. IMRW and ALM provided valuable input in the synthesis of the data for the discussion, and all authors have been actively involved in the editing of the project.

\section{Competing interests None declared.}

Ethics approval Ethics approval was obtained on February 13th 2013 from the NSW Population and Health ServicesResearch Ethics Committee (2012/09/415), Aboriginal Health and Medical Research Council of NSW (1001/14), and all Australian educational sectors: the Board of Studies (for government schools), the Australian Independent Schools and the Catholic Education Commission (D2014/120797), with approval from all data custodians. Data were made available to researchers by December 2013. Ethics approval renewal enabled researchers continued access until 1 December2015. Ethics Approval for NAPLAN analysis was granted on July 8th 2015, and data were madeavailable to researchers by August 2015

Provenance and peer review Not commissioned; externally peer reviewed.

(C) Article author(s) (or their employer(s) unless otherwise stated in the text of the article) 2018. All rights reserved. No commercial use is permitted unless otherwise expressly granted.

\section{REFERENCES}

1 Holland AJ. Pediatric burns: the forgotten trauma of childhood. Can J Surg 2006:49:272-7.

2 Teo Al, Van As AB, Cooper J. A comparison of the epidemiology of paediatric burns in Scotland and South Africa. Burns 2012;38:802-6.

3 Tomkins KL, Holland AJA. Electrical burn injuries in children. J Paediatr Child Health 2008;44:727-30.

4 Wasiak J, Spinks A, Ashby K, et al. The epidemiology of burn injuries in an Australian setting, 2000-2006. Burns 2009;35:1124-32.

5 Laitakari E, Koljonen V, Pyörälä S, et al. The long-term health-related quality of life in children treated for burns as infants 5-9 years earlier. Burns 2015;41:1186-92.

6 Kidd LR, Nguyen DQ, Lyons SC, et al. Following up the follow up-long-term complications in paediatric burns. Burns 2013;39:55-60.

7 Stone J, Gawaziuk JP, Khan S, et al. Outcomes in adult survivors of childhood burn injuries as compared with matched controls. J Burn Care Res 2016;37:e166-e173.

8 Campbell FA, Ramey CT. Effects of early intervention on intellectual and academic achievement: a follow-up study of children from low-income families. Child Dev 1994;65:684-98

9 Linkage CfHR. Guide to health record linkage services. 2013 http://www.nss.gov.au /nss/home.nsf/0/e2d861c453d7b7f6ca25756700191b53/\$FILE/CHeReL_Guide_ version\%201.3.pdf

10 Authority ACAaR. NAPLAN achievement in reading, persuasive writing, language conventions and numeracy: National report for 2014. Sydney, 2014.

11 Boden JM, Fergusson DM, Horwood LJ. Risk factors for conduct disorder and oppositional/defiant disorder: evidence from a New Zealand birth cohort. J Am Acad Child Adolesc Psychiatry 2010;49:1125-33.

12 Marks GN. Demographic and socioeconomic inequalities in student achievement over the school career. Aust J Educ 2014;58:223-47.

13 Miller PW, Voon D. School outcomes in New South Wales and Queensland: a regression discontinuity approach. Educ Econ 2014;22:427-48.

14 Kleinbaum DG, Kupper L, Morgenstern H. Epidemiologic research: principles and questionnaire methods. New York: Van Nostrand Reinhold, 1982.

15 van Baar ME, Essink-Bot ML, Oen IM, et al. Functional outcome after burns: a review. Burns 2006:32:1-9.

16 Disseldorp LM, Niemeijer AS, Van Baar ME, et al. How disabling are pediatric burns? Functional independence in Dutch pediatric patients with burns. Res Dev Disabil 2013:34:29-39.

17 D'Souza AL, Nelson NG, McKenzie LB. Pediatric burn injuries treated in US emergency departments between 1990 and 2006. Pediatrics 2009;124:1424-30.

18 Sheridan $\mathrm{RL}$, Hinson Ml, Liang $\mathrm{MH}$, et al. Long-term outcome of children surviving massive burns. JAMA 2000;283:69-73.

19 Badger K, Anderson L, Kagan RJ. Attention deficit-hyperactivity disorder in children with burn injuries. J Burn Care Res 2008;29:724-9. 
20 van Baar ME, Polinder S, Essink-Bot ML, et al. Quality of life after burns in childhood (5-15 years): children experience substantial problems. Burns 2011;37:930-8.

21 ACARA. ACARA. ' National assessment program literacy and numeracy: achievement in reading, persuasive writing, language conventions and numeracy'. 2013 http://www.nap.edu.au/verve/_resources/naplan_2013_national_ report.pdf
22 Hennessey D, Torvaldsen S, Roberts C. Linkage rate between NSW Perinatal Data Collection birth records and government school NAPLAN educational records, by gestational age at birth. Sydney, NSW: Sydney University, 2016. https://ses.library. usyd.edu.au/bitstream/2123/15755/2/PDC_NAPLAN_linkage_REPORT.pdf

23 Belfield C. The cost of early school leaving and school failure, 2008. http://s iteresources.worldbank.org/INTLACREGTOPPOVANA/Resources/BELFIELDCostofS choolFailure.pdf 